\title{
Research on the Characteristics and Correlation between the College Students' School Identity and Self-esteem in Jiangxi Province
}

\author{
Rong-hua WEN \\ College of Graduate \\ Jiangxi University of Traditional Chinese Medicine \\ Nanchang, Jiangxi, China
}

\author{
Fan-jiao ZENG \\ College of Graduate \\ Jiangxi University of Traditional Chinese Medicine \\ Nanchang, Jiangxi, China
}

\author{
Zhi-bing ZHONG * \\ Psychological Counseling Center \\ Jiangxi University of Traditional Chinese Medicine \\ Nanchang, Jiangxi, China \\ 494234679@qq.com
}

\begin{abstract}
In order to provide evidences for improving the level of college students' mental health, this study investigated the characteristics and relationships between school identity and self-esteem of the college students in Jiangxi province. Using the school identity scale and self-esteem scale, the number of 896 students from three universities in Jiangxi Province were selected for research through stratified random sampling. College students' school identity $(M=96.60, S D=14.11)$ and self-esteem( $M=30.06, S D=3.92)$ were to the level of medium on the high side in Jiangxi province; School identity and self-esteem had significantly positive correlation $(r=0.383, p<0.01)$; The score of school identity in gender and student types had no obvious differences $(p>0.05)$, but it was distinctly different in school types $(F=8.059, p<0.001)$; The score of self-esteem had no significant differences in gender and school types $(p>0.05)$, but striking difference existed in student types $(t=2.183, p<0.05)$. School identity is closely related to self-esteem, and the level of students' self-esteem can be improved by enhancing their sensation of school identity.
\end{abstract}

Keywords-college students; school identity; self-esteem; correlation

\section{INTRODUCTION}

With the development of higher education, school identity has an increasingly important impact on students' mental health. School identity is the individual recognition that belongs to the school group, and it realizes the emotional and valuable implications of joining in the school[1]. As an important indicator to measure students' mental health, self-esteem is closely related to the status of individuals' mental health. Also, it can exert a kind of wide and important influence on people's self-recognition, emotional experience, achievement motivation and social behaviors[2]. At present, the research of college students' school identity is more about the psychological adaptation, influential factors or

Project supported by the subject of Jiangxi University of Traditional Chinese Medicine(2013RW0093)

Corresponding author: Zhi-bing ZHON measurement methods, and less on the two variables of school identity and self-esteem simultaneously. In addition, participants in previous studies often came from one place and the same school, lacking the ones between different types of colleges. To this end, we conducted the following research, and the report was as follows.

\section{METHODS}

\section{A. Participants}

Stratified randomly selected 950 students from 3 colleges in Jiangxi province to conduct questionnaire survey, there were 896 valid questionnaires and the effective rate was 94.31\%. Among them, 385 (43\%) participants were from Jiangxi University of Traditional Chinese Medicine, 206 (23\%) were from Nanchang University, and the rest were from Jiangxi Normal University. Also, the number of undergraduates and postgraduates was 379 and 517, respectively takes $42.3 \%$ and $57.7 \%$; the number of males and females was 364 and 532, severally takes $40.6 \%$ and $59.4 \%$.

\section{B. Measures}

1) School Identity Scale

Using Ding Tian's college student identity scale, who compiled in 2012[3]. This scale had a total of 20 items, which was divided into four dimensions: Group Cognition, Emotional Connection, Positive Evaluation and Autonomy Behavior. The scale used 7 points, ranging from 1 (completely disagree) to 7 (fully agree). The higher the score is, the higher the school identity level is. The Crombach's coefficient of the scale in this study was 0.90 .

\section{2) Self-esteem Scale}

Using Rosenberg's self-esteem scale, who compiled in1965[4]. The scale has a total of 10 questions, 3, 5, 9 and 10 are entitled "Reverse score questions". The scale used 4 points, ranging from 1 (very inconsistent) to 4 (very consistent). The 
higher the score is, the higher level of the self-esteem is[5]. The scale is widely used at home and abroad, which has a good reliability and validity. The Crombach's coefficient of the scale in this study was 0.847 .

\section{3) Statistical Analysis}

SPSS20.0 software is to be selected for statistical analysis of this study, using the methods of descriptive statistics, independent sample $\mathrm{T}$ test, analysis of variance, correlation analysis, regression analysis and others.

\section{RESULTS}

\section{A. The General Characteristics of College Students' School Identity and Self-esteem in Jiangxi Province}

Table1 showed that the school identity scale had a mean total of $96.60(S D=14.11)$, which was higher than the median value of 80.00 . The average of the four dimensions of Group Cognition, Emotional Connection, Positive Evaluation, and Autonomy Behavior was also higher than theoretical median. It showed that the college students' school identity score in Jiangxi province was at a moderately high level. The self-esteem scale had a mean total of 30.06 ( $S D=3.92)$, which was higher than the median value of 20.00. That means the score of college students' self-esteem in Jiangxi province was at a moderately high but low level.

\section{B. The Differences in Gender, Student Types and School} Types of College Students' School Identity and Self-esteem in Jiangxi Province

Table2 showed that gender differences in school identity and self-esteem were not significant $(p>0.05)$. The difference of student types in school identity score was not clear $(t=0.694$, $p>0.05$ ), but there was a most visible difference in self-esteem score $(t=2.183, p<0.05)$. The self-esteem score of postgraduates was strikingly higher than that of the undergraduates. The difference of school types in school identity score was also clear( $F=8.059, p<0.001)$. The school identity score of comprehensive university was significantly higher than that of the normal and medical universities, but the difference of school types in self-esteem score was not $\operatorname{distinct}(F=2.688, p$ $<0.05)$.

TABLE I. DESCRIPTIVE ST ATIST ICS OF COLLEGE STUDENTS’ SCHOOL IDENTITy AND SELF-ESTEEM IN JiANGXi PROVINCE(N=896).

\begin{tabular}{ccccccc}
\hline Statistics & Self-esteem & School Identity & Group Cognitive & Emotional Connection & Positive Evaluation & Autonomous Behavior \\
\hline $\bar{x} \pm s$ & $30.06 \pm 3.92$ & $96.60 \pm 14.11$ & $18.13 \pm 3.51$ & $25.30 \pm 4.44$ & $22.24 \pm 4.84$ \\
Midpoint & 20.00 & 80.00 & 16.00 & 20.00 & 20.00 \\
Title Number & 10 & 20 & 4 & 5 & 5 \\
\hline
\end{tabular}

TABLE II. THE DIFFERENT ANALYSISIN GENDER, STUDENT TyPES AND SCHOOL TYPES OF COLLEGE STUDENTS’ SCHOOL IDENTITY AND SELF-ESTEEM IN JIANGXI PROVINCE.

\begin{tabular}{|c|c|c|c|c|c|c|c|}
\hline & Factor & School Identity & $t / F$ & $\begin{array}{c}\text { Multiple } \\
\text { comparison }\end{array}$ & Self-esteem & $\mathrm{t} / \mathrm{F}$ & $\begin{array}{c}\text { Multiple } \\
\text { comparison }\end{array}$ \\
\hline \multirow[t]{2}{*}{ Gender } & Male(N=364) & $4.88 \pm 0.72$ & & & $3.03 \pm 0.40$ & & \\
\hline & Female(N=532) & $4.80 \pm 0.69$ & 1.588 & & $2.99 \pm 0.39$ & 1.309 & \\
\hline \multirow{3}{*}{$\begin{array}{l}\text { Student } \\
\text { types }\end{array}$} & Undergraduate(N=379) & $4.81 \pm 0.70$ & & & $2.97 \pm 0.41$ & & \\
\hline & Postgraduate(N=517) & $4.84 \pm 0.71$ & 0.694 & & $3.03 \pm 0.38$ & $2.183^{*}$ & \\
\hline & (1)Normal type(N=305) & $4.84 \pm 0.68$ & & (2) $>$ (1) & $3.00 \pm 0.39$ & & \\
\hline \multirow{3}{*}{$\begin{array}{l}\text { School } \\
\text { types }\end{array}$} & (2) Comprehensive type $(\mathrm{N}=206)$ & $4.98 \pm 0.73$ & $8.059^{* * *}$ & (2) $>$ (3) & $3.06 \pm 0.41$ & 2.668 & \\
\hline & (3)Medical type(N=385) & $4.74 \pm 0.69$ & & & $2.98 \pm 0.39$ & & \\
\hline & Total(N=896) & $4.83 \pm 0.71$ & & & $3.00 \pm 0.39$ & & \\
\hline
\end{tabular}

TABLE III. THE CORRELATION ANALYSIS BETWEEN SCHOOL IDENTITY AND SELF-ESTEEM

\begin{tabular}{|c|c|c|c|c|c|}
\hline Item & School Identity & Group Cognition & Emotional Connection & Positive Evaluation & Autonomous Behavior \\
\hline Self-esteem & $.383^{* * * *}$ & $.258^{* * * *}$ & $.334^{* * * *}$ & $.272^{* * * *}$ & $.385^{* * *}$ \\
\hline
\end{tabular}

4) The Correlation Analysis between School Identity and Self-esteem

Table3 showed that there was a distinctly positive correlation between school identity and self-esteem $(r=0.383$, $p<0.001)$. Among them, a significant positive correlation exists between self-esteem and group cognition $(r=0.258$, $p<0.001)$, self-esteem and emotional connection $(r=0.334$, $p<0.001)$, self-esteem and positive evaluation $(r=0.272$, $p<0.001)$, also, self-esteem and autonomous behavior $(r=0.385$, $p<0.001$ ).
5) The Regression Analysis between School Identity and Self-esteem

Taking the school identity score as a predictor and the self-esteem score as a dependent variable, regression analysis results showed that the school identity can positively predict students' self-esteem ( $t=12.384, p<0.001)$. The regression equation established was: $\hat{y}=19.777+0.106 \mathrm{x}$. 
TABLE IV. THE REGRESSION ANALYSIS OF SCHOOL IDENTITY TO SELF-ESTEEM.

\begin{tabular}{cccccc}
\hline Dependent Variable & Predictor Variable & $\mathrm{B}$ & $\beta$ & $t$ & $\mathrm{R}^{2}$ \\
\hline Self-esteem & School Identity & .106 & .383 & $12.384^{* * * *}$ & .146 \\
\hline \multicolumn{5}{c}{ Note: $\mathrm{P}<0.05,{ }^{* * *} \mathrm{P}<0.01,{ }^{* * * *} \mathrm{P}<0.001$} \\
\end{tabular}

\section{DISCUSSION}

\section{A. The Characteristics of College Students'School Identity in Jiangxi Province}

This study found that the score of college students' school identity in Jiangxi province was only moderately high and did not show a high level. The reason for it may be that the sense of college students' belonging and acceptance for their own school is still vague, in other word, they have not yet understood what it means to be a member of their school that give them emotional and self-worth. Secondly, students' college reputation is not high, and college students themselves feel that school visibility and social influence are low, which is not enough to give them a strong sense of pride. There were no significant differences in school identity between the gender and student types in this study, but some differences in the school types. The male and female students, undergraduates and postgraduates in colleges, are all in the same school environment, and they enjoy consistently learning resources, equal rights and opportunities, so there are no significant differences in school identity between the gender and student types. The school identity score of students from comprehensive type universities was clearly higher than that of normal and medical college students, this may be related to the students' perception of university discrimination: comprehensive universities are relatively professional ones compared with the medical and normal universities, which have richer educational resources, more complete professional categories, more comprehensive rankings, and higher social awareness. Therefore, comprehensive college students have a higher degree of school identity score.

\section{B. The Characteristics of College Students'Self-esteem in Jiangxi Province}

The study discovered that the score of college students' self-esteem in Jiangxi province was at a relatively high level, showing a high sense of self-esteem. The reason for this result may be the change of students' status. After a fierce examination competition, they became an undergraduate or postgraduate student, receiving social recognition and praise, so they will be more confident in their own abilities and their sense of self-esteem will be enhanced. In this study, there were no significant differences in self-esteem between the gender and school types, but the student types had significant differences in self-esteem. Male and female students in self-esteem had no big difference, this may because of the development of the society and the progress of the concept that men and women have equal rights and opportunities in learning and living in the same school and receiving the same education. The student types had no significant differences in self-esteem. Although different types of colleges have some differences in subjects and career goals, there is no much difference in the overall learning environment; therefore, the school types had no significant differences in self-esteem.
Postgraduates' self-esteem was significantly higher than that of the undergraduates. Compared with undergraduates, postgraduates have higher levels of academic qualifications, richer knowledge reserves, broader vision, and more mature ideas, so, under the same school environment, postgraduates have more confidence and superiority.

\section{The Correlation between School Identity and Self-esteem}

There was a significant positive correlation between college students' school identity and self-esteem in Jiangxi province. School identity can positively predict college students' self-esteem. This was also consistent with the conclusions of Benish-weisman M, Daniel E[6] and Lin Hui[7]. In the special organization of the school, the students' self-esteem will be enhanced when the school shows the importance and care to the students[7]. This can further suggest that we can effectively improve the level of self-esteem by intensifying the sense of school identity among college students.

\section{Research Suggestions and Deficiencies}

The research showed that some college students still have lower school identity and self-esteem experience. In view of this part of students, it is necessary to conduct their positive emotions and mental health counseling in a timely manner. Because, if they can't improve their sense of self-esteem; it is extremely detrimental to their physical and mental health and academic development. Above all, it also reflects that this study is very necessary. For the moment, the development of college students' psychological health should arouse social concerns.

Finally, there were still some deficiencies in the process of this study. The type of school in this study was too single, being lack of comprehensiveness, and the number of student samples was not enough, which may cause deviations of the research results. The future research should diversify the sample sources, increasing the number of participants, and avoid the limitations of the results.

\section{CONCLUSION}

In conclusion, the score of the college students' school identity and self-esteem in Jiangxi province were both in middle to high level. School identity and self-esteem have significantly positive correlation, and the school identity can positively predict students' self-esteem. Therefore, we can improve the level of students' self-esteem by enhancing their sense of school identity experience.

\section{REFERENCES}

[1] Huang Silin,Han Mingyue, Ning Caifang, LIN Chongde. School identity promotes sense of responsibility in college students: The mediating role of self-esteem[J]. Acta Psychologica Sinica, 2016,48(6): 684-692.(In Chinese) 
[2] Ayano Yamaguchi, Satoshi Akutsu, Atsushi Oshio, Min-Sun Kim. Effects of cultural orientation, self-esteem, and collective self-esteem on well-being. Psychological Studies, 2017, 62(3): 241-249.

[3] Ding Tian. The Empirical Research on the Antecedents and Consequences of College Students' school identification[D].Hunan: Xiangtan University,2012.(In Chinese)

[4] Rosenberg, M. (1965). Society and the adolescent self-image. Princeton, NJ: Princeton University Press
[5] Tian Xiaolu. The Chinese version of the Rosenberg(1965) self-esteem scale is a fly in the ointment. Psychological Exploration, 2006,2:88-91. (In Chinese)

[6] Benish-Weisman M, Daniel E, S chiefer D, et al. Multiple social identifications and adolescents' self-esteem[J]. J Adolesc, 2015(44):21-31.

[7] Lin Hui, Pan Xiao-xin, Chen Xin-miao. Study on the Relationship among College Identify, Collective Self-esteem and Life Vis io of College Students[J].Minnan Normal University Journal(Nature Science Edition) 2015,01(018): 120-125.(In Chinese) 